\title{
The Value of Volunteering among Arab Students in the Hebrew Teacher Training Program-As a Factor of Adjustment \& Contribution to the Arab Society
}

\author{
Janan Faraj Falah* \\ The Arab College of Education of Haifa, Haifa, Israel \\ Email: Jananf81@gmail.com
}

How to cite this paper: Falah, J.F. (2019) The Value of Volunteering among Arab Students in the Hebrew Teacher Training Program-As a Factor of Adjustment \& Contribution to the Arab Society. Open Journal of Social Sciences, 7, 421-426. https://doi.org/10.4236/jss.2019.77034

Received: February 11, 2019

Accepted: July 27, 2019

Published: July 30, 2019

Copyright $\odot 2019$ by author(s) and Scientific Research Publishing Inc. This work is licensed under the Creative Commons Attribution International License (CC BY 4.0).

http://creativecommons.org/licenses/by/4.0/ (c) (i) Open Access

\begin{abstract}
In the last decade, the value of volunteering among the Arab society has evolved to different state aspects in general, and within the Arab society in particular. Many institutions have embraced volunteerism as a moral value, upgrading it in a manner that would adjust to the traditional society mindset. In the past, volunteering had a basic narrow value, aiming especially to charity and aiding of students in homework and cleaning of public areas. During the time, this value has been extended to purposes of identity formation and fulfillment of humanitarian and social duties. In view of the above, the question is how students would develop the value of volunteering in the course of preserving the traditional patterns of the Arab society.
\end{abstract}

\section{Keywords}

Training Students, Volunteering, Arabic Community, Hebrew Language Instruction, Elderly Arab Women, Values

\section{Volunteering}

Volunteering is a willingly act, free of charge aiming for the sake of the community. In Israel, $18 \%$ of the adult population volunteers, yet , it is relatively lower in comparison to Western countries (Bar \& Dror, 2015) [1], while the percentage

$\left.{ }^{\star} 1\right)$ Dr. Janan Falah, the author of this article is a lecturer and a pedagogical counselor in the department of teaching the Hebrew language and gender at the Haifa Arab College. 2) AKKO Women Vision Association is an Arab-Jewish association that was established and directed by Dr. Janan Falah in order to empower women in the bi-national city of Acre through culture and sharing of life, and to gain peace in the country and all over the world. 
of volunteering students is over $70 \%$, \% of the general volunteering community, consisting of 3 hours per week (Levental, Hendy \& Canaan, 2009) [2]. Moreover, the percentage of Jewish volunteering students is higher than the percentage of Arab students, due to the complexity of the Arab society and its unique volunteering value perception. The Arab community consists of large families, which are bonded in relationships by blood and marriage, and broader relations. Its codes include primarily aid and assistance, for example, at the time of celebration, the family and neighbors immediately enlist to assist the groom's or the bride's family, or in cases of grief, the family and neighbors also enlist help in preparing the mourning tent, cooking for the family and babysitting the children. Although this aid is spontaneous and not formal, and there are no clear rules, in contrast to formal volunteering programs, still, the formal programs encounter assimilation difficulties among the population (Leffler, Bshara, 2010) [3], due to the complexity of the Arab society. Many projects have been adapted to this special society in order to support the volunteers, especially students and teenagers, mostly to generate social involvement, and at the same time to reward them-by adding credits to their studies or by awarding a scholarship.

A combination of state-sponsored volunteering projects has increased awareness towards the value of volunteering, conveying subconscious messages that volunteering assists better integration in society and relative easier management with adults, maintenance of orientation to service and help of others.

Numerous studies indicate that volunteers not only put hardworking in the process of giving, they are also affected positively, for they learn to respect others, to be satisfied, as well as to develop social skills, to strengthen confidence and better decision-making, and fostering social responsibility (Hadar, 2010) [4].

Voluntary activity among Arab citizens "opens a door" towards better integration to the Israeli society and to better cooperation between the participants of the various project groups. Joined goals would develop social relations between the groups and greater involvement of Arabs in Israeli society. At this phase, it is important to note that social partnership in Israel is not done by religious, national means, it is merely social, for the majority of the Arab nation in Israel aspire for peace and equality, they support the establishment of a Palestinian State in the West Bank, yet, at the same time demand legal and social equality to the Jewish society (Abu-Asbah, 2011) [5]; thus, the phenomenon of volunteering to National Service has increased among the young Arab population.

\section{Hebrew Teaching Students}

The Hebrew teaching students in the Arab College of Education of Haifa, gain practice in Acre schools, in addition to this practice, they are obligated to volunteer one hour per practice with elderly citizens.

Ten years ago, the pedagogical counselor in the Arab College has developed this extensive volunteering system in different various frames (1) thus, by the end of the academic year a student gets a diploma with an additional bonus 
score on practical workshop.

For the purpose of this study, two volunteering frames have been selected, the first is the volunteering at the Arab Elderly House (Faraj Falah 2017) [6] in the old town of Acre, the second is volunteering at the Women's Peace House which is part of the Women's Vision Association in Acre [2] (Falah Faraj 2017) [7], in both models, the students teach basic Hebrew lessons to elderly Arab women, with the guidance of pedagogical counselor in each session.

It is extremely important to teach the Hebrew language, for it is the first official language of the State, this is the reason that the Arab sector is obligated to learn the Hebrew language since the establishment of the State, in order to create integration and accessibility to the State's institutions (Wated, 2010) [8], in the course of maintaining their native language, for language is the "seal" of ethnic identity. Hence, the official languages in Israel are Hebrew and Arabic (Shala'ta, 2010) [9].

\section{The AKKO Women Vision Association-Arabs and Jews Working Together}

In view of what has been written above, the Acre Vision Association with the participation of Arab and Jewish women has been operating since 2003 to promote brotherhood and peace in the city, by maintaining various elevating models towards dialogue between the two societies. The Association hosts women at all ages and keeps providing their needs in all levels and aspects, by recruiting young volunteers and professionals to set up workshops and lectures about the role of society and women's in particular.

At the phase of the Association's emerge, many Arab women expressed their will to integrate in its activity, yet, many of the older women were worried due to the language barrier, thus, many of the questions revolved around the nature of the meetings when both sides do not speak the other language, a fear which eventually led to the development of differential methods for teaching the other language, a great educational challenge towards peace and coexistence in the city of Acre.

For the sake of the idea, the students of Hebrew teaching in the Arab College of training of teachers were recruited to volunteer in the Association as part of their learning framework, to enable the Arab women to manage a basic conversation with Jewish. The students expressed their willingness to participate in the project as part of their practice.

At the beginning, it was important to examine the interaction between the students and the elderly women, especially due to the age differences and perceptions, after one day of experiencing; it seems that both sides have expressed willingness to participate.

This study examines the value of volunteering among the Arab students, the extent of their involvement in the project, and the extent of social and mental modification after one year of practice with elderly third generation women. 


\section{Research Method}

The study was conducted in a qualitative method, including lessons observations and half-structured interviews with the project's participants, in order to examine the participants' experiences during the study.

The study population includes:

Hebrew teaching Students of the Arab College for training of teachers. In the last year, 15 students participated in the project; they were teaching Hebrew in the Association once a week.

Research objectives:

To examine the value of volunteering among the students, the modification behavior patterns among the elder women, and the effect of the teaching of Hebrew as a basis for social leverage towards integration in the Israeli society.

\section{Findings and Discussion}

The findings of the study are divided into four categories, the first part examines the experience of volunteering at the Senior Citizen (women's) House, the second part discusses the students' expectations from the project, the third part focuses on the students' transformation as a result of exposing to the behavior patterns of the third age, the fourth part examines the elderly women's extent of learning of the Hebrew language.

All the interviewed students have defined the experience as thrilling, (P.) describes this as fascinating moving experience, for its noble and satisfying cause, especially after she has succeeded to delight an elderly woman, not only by pedagogical means. Thus, the official primarily pedagogical aim has changed, becoming an encounter of love with a sense of belonging.

(L.) also describes of similar feelings, claiming that volunteering was not merely for the sense of giving and helping others, it also had a personal aspect "I have met amazing people, made new friends in the course of volunteering, and moreover, volunteering with the third age has made me look at my life differently, especially after talking to the senior women about their life, which has led to a great change in my own life perspective".

Fidda, a four year student, describes her experiences in the Center as a mixture of sadness and joy, an extremely exciting encounters and dialogues which have led to new insights and changes, and becoming more patient and calm. "After hearing their amazing stories it made me laugh, especially at the beginning of the voluntary, in the phase of teaching letters that was followed by loud laughter in the room.

Many of the students (9 students) had doubts regarding this volunteering, they were afraid from the encounter with the elderly women and the age gaps, especially fearing the first encounter, how would the elderly women will accept them and their attitude towards learning Hebrew, a language that they never had learned, only by hearing. The doubts concerned also the duration of the lesson. (W.), a four year student, admitted that right after the first encounter, coming 
was merely to complete her academic obligations-a technical procedure with no great expectations, the feeling was reversed, the first encounter was actually stimulating and challenging, she began to develop expectations towards the encounters, regretting that she had not participated in other volunteer programs, due to fearing encountering strangers.

Another factor which has been tested in the interviews and observations is the extent of preserving the culture and identity among the volunteering students, most participants describe an experience of connecting to their roots due to the sessions with the senior citizens, if by the seniors' stories or by traditional dishes. The transformation has occurred after few encounters, leading to a change of thinking, as Linna describes, "I didn't taste this kind of food, our main dishes these days include fat and unhealthy food, after the elders explained me in detail the element of cooking rice and fish (Mahaga Syria), I wonder why we do not maintain traditional Arab food that is very healthy and unique, and imitated and upgraded around the world and rather giving it up. I feel my generation lose tradition and heritage, the responsibility to preserve this heritage is ours".

The last part discusses the manner that elderly women cope with the initiative to learn Hebrew at this age, as Fadi describes, "The elderly women were interested in learning as part of their spare time at the Center, when I explained to them that we're going to teach them Hebrew, most of them laughed, one of them finally said, 'Fine, at last I'll manage to understand the HMO'”. Fadi explains that they began to learn letters and words, yet, their first intention did not include learning Hebrew, it was mainly to pass time, after few sessions of teaching letters and sentences, they have become curious asking questions as-how to turn Arab sentences into Hebrew, to learn useful "key words" such as HMO, social security, a cab, etc. Morphologically, they did not know how to associate the words they had heard and put together into sentences on order to conduct a dialogue with Jewish people, especially within the Centre. For the elderly, It was very important to be able to speak and understand the Hebrew language, finally, Fadi adds the importance of volunteering out of real choice and desire rather than being compulsory, this is the role of Education, to raise awareness towards social modification by training of teachers and students towards changing the Israeli society status quod, and creating an equal and just society for all ethnic groups (Perry, 2007) [10].

The initiative the students were taken part in is a small sample which does not reflect the Arab society in General, yet, its success is tremendous and should also be applied to other groups in the society, in order to develop social involvement and better integration.

\section{A Summary}

The volunteer enterprise among Arab students, especially at the Elderly House in Acre and the Peace Vision Association, has led to a change of concept among the students, personally and socially, for example, the students testify that this 
volunteering has affected their attitude towards the Arab tradition and its preservation, due to their exposure to the elderly's special stories about the history of the Arab society that apparently they were not exposed or aware to; furthermore, the value of volunteering in itself has given an extra meaning to unconditional giving and a peace of mind as is well proved by observing the activities in the Center. All these elements have made to students' personal commitment towards the elderly women not merely for academic reasons, scholarship or other kinds of materials rewarding.

\section{Conflicts of Interest}

The author declares no conflicts of interest regarding the publication of this paper.

\section{References}

[1] Bar, R. and Dror, N. (2015) Between Theory and Practice: The Inter-Sectoral Volunteer Project for the Advancement of Volunteering and Social Participation in Relation to Collective Impact. Et Hasade, 15, 98-109.

[2] Levental, D. and Canaan, R. (2009) Student Volunteering in Israel from Comparative Perspective: Predictions, Motives, Rewarding and their Impact on Educational Institutions. Social Secure, 79, 141-163.

[3] Leffler, N. and Bshara, E. (2010) Volunteering among the Arab Society in Israel as a Tool for Improving Life. Et Hasade, 4.

[4] Hadar, L. (2010) Volunteering as a Tool for Empowering Youth at Risk from the Stage from Disengagement to Integration. 16, 43-60.

[5] Abu Asba, H. and Varod, G. (2011) The Identity of Israeli-Palestinian Youth, the Extent of Identification with the Israeli State \& the Jewish Culture in Aspect of Education. The Mofet Institute, Tel Aviv-Yafo, 52.

[6] Faraj Falah, J. (2017) Humor among Elderly Arab Women of the Elderly House of Acre. Humor Online.

[7] Faraj Falah, J. (2017) Women Can Do It: The Role of Akko Women Vision Association (AWVA) on Bringing the Two Nations (Arabs and Jews) Together. International Journal of Non-Governmental Organizations (NGOs) and Essays (IJNGOE), 2 .

[8] Wated, E. and Manor, R. (2010) Training Arab Teachers to Teach Hebrew at the Academic Institute for Arab Teachers, The Bet-Berl College-An Update. Mofet Institute Journal, 44, 36.

[9] Shalata, G. and Mahajna, M. (2010) Language Policy in Educational Institutions and Higher Education: Strategies in Language Teaching Training for in Teacher Training Colleges. Mofet Institute Journal, 44, 22.

[10] Perry, P. (2007) Education in Multi-Cultural Society: Ploralism \& Meeting Points between Cultural Rifts. Jerusalem, Carmel, 13. 